\title{
Balanços energéticos agropecuários: uma importante ferramenta como indicativo de sustentabilidade de agroecossistemas
}

\author{
Agricultural energy balance: an important tool as indicative of sustainability \\ of agricultural ecosystems
}

Alessandro Torres Campos ${ }^{1}$ Aloísio Torres de Campos ${ }^{2}$

\section{-REVISÃO BIBLIOGRÁFICA-}

RESUMO

No Brasil, pouca atenção se tem dado às formas $e$ caminhos com que os fluxos energéticos se distribuem nos sistemas produtivos. Na agropecuária, a atenção tem sido voltada a novas fontes de energia (biomassa) ou em tecnologia alternativa, visando a racionalização do uso de energia fóssil ou elétrica. Entretanto, a agricultura tem se desenvolvido baseada fortemente na utilização intensiva de máquinas agrícolas, com conseqüente uso de combustíveis fósseis. Um fator de estrangulamento muito forte no consumo energético geral tem sido a utilização massiva de fertilizantes derivados do petróleo nos agroecossistemas. Estudos de Balanços Energéticos visam determinar os pontos de estrangulamento energético fundamentando a busca por tecnologias poupadoras de energia, especialmente aquelas de origem fóssil (combustível, fertilizante, agrotóxicos, energia despendida na fabricação das máquinas e implementos, etc.). No Brasil, a Região Sul, é onde se encontram vários trabalhos buscando uma agricultura mais auto-sustentável, do ponto de vista da utilização da energia. Em vista da possibilidade de eventuais futuras crises energéticas, o presente trabalho procura analisar o estado-da-arte dos estudos em Balanço Energético, no Brasil e no Mundo, como uma ferramenta de indicação da sustentabilidade dos sistemas agropecuários.

Palavras-chave: balanço de energia, eficiência energética, conservação de energia, estruturas rurais.

\section{ABSTRACT}

In Brazil, little attention has been given to the ways energy flows are distributed in the productive systems. In the agriculture, the main focus was directed to new sources of energy (biomass) or in alternative technology, aiming to a rational use of the fossil and electric energy. However, the modern agriculture has been based on massive machines utilization, with a consequent use of fossil fuel. A hard strangulating factor in the general energy consumption has been the intensive use of fertilizers derived from petroleum in the agricultural ecosystems. The agricultural energy system has been developed based on intensive use of fertilizers derivate from petroleum. Studies considering Energy Balance, aim to determine the weak points of those systems and establish the fundaments for energy saver technologies especially fossil source (fuel, fertilizer, pesticides, energy expended in machines, implements, etc.). In Brazil, the South Region where important programs have been developed for a more sustainable agricultural systems according to energy utilization. Under the perspective of eventual energy crisis in the future, the present work was done to analyze the state of the art of Energy Balance studies in Brazil and in the world, as an instrument of sustainability indication in agricultural systems.

Key words: energy inputs and outputs, energy efficiency, energy conservation, rural structures.

\section{INTRODUÇÃO}

A energia de origem fóssil desempenha papel vital nos sistemas de produção agrícola, pois seu preço afeta todos os custos da cadeia produtiva (FLUCK, 1979). Energia e produção de alimentos estão de tal forma inter-relacionadas, que qualquer impacto nos custos do petróleo transmitem-se e ampliam-se ao longo da cadeia alimentar. Com grande influência no sistema produtivo agrícola, torna-se importante a determinação criteriosa de metas e prioridades, dos pontos em que a pesquisa agropecuária pode dar a sua contribuição na busca pela redução da dependência do uso de derivados do petróleo (RIVALDO, 1988). Na questão energética do país, pouca importância tem sido dada ao balanço energético, sendo as investigações quase sempre

\footnotetext{
${ }^{1}$ Engenheiro Agrícola, Doutor, ProfessorAdjunto, Centro de Ciências Agrárias, Universidade Estadual do Oeste do Paraná (UNIOESTE), Rua Pernambuco, 1777, 85960-000, Marechal C. Rondon PR. Tel. (45) 254 3216. E-mail:atcampos3@yahoo.com.br. Autor para correspondência. ${ }^{2}$ Engenheiro Agrônomo, Doutor, Pesquisador, Embrapa Gado de Leite, Juiz de Fora/MG.
} 
direcionadas à busca por novas fontes, a partir de culturas com alto potencial de produção calórica (CARMO et al., 1988; CARMO \& COMITRE, 1991).

O balanço energético visa estabelecer os fluxos de energia, identificando a demanda total e eficiência, refletida pelo ganho líquido e pela relação saída/entrada. Nesse processo, quantificam-se todos os insumos utilizados e produzidos que são transformados em unidades de energia. A estimativa dos balanços de energia e de eficiência energética são importantes instrumentos no monitoramento da agricultura ante o uso de fontes de energia não renováveis (Hetz 1994, citado por SIQUEIRA et al., 1999; BUENO et al., 2000).

Em uma investigação na produção de milho nos Estados Unidos, avaliando a relação (kcal produzida)/(kcal consumida), PIMENTEL et al. (1973) verificaram um decréscimo de 3,7, em 1945, para 2,8, em 1970. Apesar do rendimento médio do milho ter aumentado aproximadamente 2,4 vezes, a média dos insumos energéticos utilizados aumentou de 0,9 para 2,9 milhões de kcal (3,1 vezes). A avaliação da energia gerada nos processos agrícolas, seja para alimentar a população, ou como combustível, para substituir os derivados de petróleo, permite verificar se o setor agrícola está ou não, cumprindo esses objetivos, ou de que forma poderia ser conduzido (CASTANHO FILHO \& CHABARIBERY, 1983). A importância da análise do balanço energético é fornecer parâmetros necessários para mensurar, interpretar e subsidiar a tomada de decisões (COMITRE, 1993).

O presente trabalho tem como objetivo analisar as pesquisas relacionadas com os balanços energéticos como forma de avaliar a sustentabilidade de processos produtivos agrícolas, no Brasil e em outros países.

\section{A energia e as crises energéticas}

A agricultura é caracterizada pela produção (alimentos, fibras, combustíveis como lenha e álcool, resíduos orgânicos como palhas, folhas, estercos) e pelo consumo de energia (energia solar, ar, água, nutrientes orgânicos e minerais do solo) e pela energia adicionada pelas forças humana e animal, fertilizantes e óleo diesel (COSTA BEBER, 1989). A lei da entropia indica que a energia tende a degradar-se nos processos de utilização, transformando-se de formas úteis em não-úteis, com tendência ao equilíbrio energético global. A lei da entropia deve estimular a poupança energética e definirá comportamento dos indivíduos com relação à natureza (GUERRERO, 1987).

O alerta sobre a escassez relativa de combustíveis fósseis foi transmitido pelos principais países produtores, em outubro de 1973, gerando uma sextuplicação dos preços, o que repercutiu como uma verdadeira catástrofe, pois a agricultura mundial depende desses insumos (FERREIRA \& ULBANERE, 1989).

Ironicamente, uma crise pode ter seu lado positivo. CLEVELAND (1995) percebeu clara resposta dos produtores a aumentos de preços, resultando em mudanças técnicas e administrativas que promovem aumento da eficiência energética. $\mathrm{O}$ autor detectou aumento global significativo no uso de energia de 1910 até 1970, e uma troca da gasolina por óleo diesel e eletricidade. O uso de todos tipos de combustíveis caiu na década de 1980. Medidas de eficiência energética na produção mostram um declínio substancial até a década de 1970, com substituição de potência animal por mecânica, devido ao baixo preço dos combustíveis fósseis em relação aos outros “inputs”. A eficiência energética na produção subiu na década de 1980 devido à diminuição na taxa de uso de energia.

Classificação das formas de entrada de energia visando ao balanço energético

Uma forma de classificação das entradas de energia, é a divisão nas categorias "Biológica”, "Fóssil" e "Industrial”, como se depara no trabalho de CARMO et al. (1988). Na primeira, consideraramse as energias humana e animal, resíduos de animais e da agroindústria, sementes e mudas, alimentos para animais, adubação verde e cobertura morta; na segunda, os produtos e subprodutos do petróleo, tidos como fontes de energia primária, incluindo adubos químicos e agrotóxicos; e na terceira são incluídas as máquinas e equipamentos agrícolas à tração mecânica e animal e a energia elétrica. Este método foi seguido, por exemplo, por CARMO \& COMITRE (1991) e BUENO (2002). COMITRE (1993) propôs uma divisão semelhante, tendo, porém, duas grandes matrizes de energia: Direta (biológica, elétrica e fóssil) e Indireta (Industrial, composta por máquinas, calcário, adubo formulado, inseticida e herbicida).

Conforme citação na literatura, a energia consumida na agricultura pode apresentar, ainda, a seguinte classificação: a) Energia que não é utilizada diretamente pelo processo produtivo. É aquela utilizada pelo homem para seu bem-estar (iluminação, aparelhos eletrodomésticos, etc.) e nos trabalhos após a colheita (operações de beneficiamento, transporte, etc.); b) Energia utilizada em operações agrícolas que tornam possível o processo produtivo ou que o torna mais eficiente, mas não fazem parte do produto final, como a fornecida pela mão-de-obra, pelos animais

Ciência Rural, v.34, n.6, nov-dez, 2004. 
de trabalho e pelas máquinas em operações de aração, gradagem, semeadura, adubação, aplicação de agrotóxicos, podas, capinas e colheita; c) Energia convertida em produto final, gasta na manutenção e no crescimento de animais e plantas ou que será armazenada na forma de alimento ou de material combustível. Incluem-se aqui a energia solar utilizada na fotossíntese, e a contida nos nutrientes do solo e nos fertilizantes (ou nos alimentos, no caso de animais), conforme metodologia adotada por JUNQUEIRA et al. (1982), em trabalho no qual estudaram as formas de uso de energia na agricultura. Entretanto, a forma de classificação da energia mais utilizada tem sido a divisão em energia direta e energia indireta, como se observa nos trabalhos de DELEAGE et al. (1979), ZUCCHETTO \& JANSSON (1979), ULBANERE \& FERREIRA (1989), PELLIZZI (1992), CLEVELAND (1995), CAMPOS et al. (2000), CAMPOS (2001), CAMPOS et al. (2003), entre vários outros.

Quando se trabalha com dados estatísticos ou estimativas, muitas vezes não se dispõe de dados de consumo de combustíveis fósseis. Neste caso, para estimativa, CLEVELAND (1995) sugere a utilização da equação: $\quad \mathrm{TE}_{\mathrm{F}}=\sum_{i=1}^{n} p_{i} x_{i}$

em que $\mathrm{TE}_{\mathrm{F}}=$ Despesa total, em reais, em combustíveis fósseis; $p_{i}=$ Preço nominal do combustível tipo $i$ (reais por kcal); $x_{i}=$ Quantidade de combustível, tipo $i$, comprado e usado nas fazendas (kcal); $n$ = Número de combustíveis fósseis utilizados. $\mathrm{Na}$ categoria energia indireta se enquadram as manufaturas de entrada ("input”) usadas no sistema agrícola, tais como maquinaria.

Energia consumida pelo trabalho humano

Considerado como clássico, o trabalho de

PIMENTEL et al. (1973), além de vários aspectos importantes da utilização da energia no desenvolvimento da agricultura, também discorre sobre a questão da utilização do trabalho humano. Caracterizando energeticamente a agricultura, os autores apresentam vários dados relativos à evolução, de 1945 a 1970. A utilização de mão-de-obra na cultura do milho nos EUA reduziu de 57 para 22 horas para cada hectare cultivado. Enquanto o emprego de energia na forma de trabalho humano decresceu $40 \%$, na forma de trabalho mecanizado aumentou em 234\%. O rendimento energético reduziu de 3,70 para 2,82, fato que instigou vários pesquisadores pelo mundo a desenvolverem estudos de balanços energéticos.

Uma interrogação que se faz é se seria lógico buscar a conversão do trabalho humano para unidades de energia. Entretanto, medidas da energia proveniente da mão-de-obra têm sido vastamente utilizadas devido ao valor de energia intrínseco que o trabalho muscular possui e também devido ao conteúdo energético do alimento consumido pelo trabalhador. Mais importante, a mão-de-obra, em muitos casos, é substituível, até certo ponto, por outras fontes de entrada (“inputs”) de energia no sistema produtivo (FLUCK, 1981). O consumo de energia pelo trabalho humano é uma parte interessante e controvertida no contexto dos balanços energéticos da produção agrícola, uma vez que os autores na área, muitas vezes, possuem idéias e argumentos diferenciados. FLUCK (1981) já ressaltava que numerosos métodos e muita confusão existe com relação à avaliação da energia contida no trabalho. A dificuldade de avaliar o trabalho humano começa ainda na escolha da delimitação do sistema. De fato, diferentes limites do sistema podem promover diferentes definições de trabalho humano (GIAMPIETRO \& PIMENTEL, 1990).

A energia consumida por trabalhadores pode ser estimada por meio de equipamento denominado "respirômetro Max Planck", com o que se avalia somente a energia diretamente empregada nas atividades, no exato momento de sua execução. Em trabalhos realizados na produção de uvas, CARVALHO et al. (1974) determinaram que um homem de 39 anos, com 75,5 kg de peso, por exemplo, consome de 3,68 a 9,20 $\mathrm{J} \mathrm{min}^{-1}$, em trabalho de conduzir trator. Um dia de trabalho é normalmente estimado, segundo FLUCK (1976), como consumidor de 2.000 a $3.500 \mathrm{kcal}$. Mas o autor alerta para o fato de que um trabalhador rural consome muito mais energia do que aquela representada pelo alimento ingerido. Há que se considerar a energia adicional utilizada em vestuário, abrigos ou moradia, transporte, educação, etc.

As características da atividade agrícola a ser explorada também podem provocar diferenciação no nível de utilização de trabalho humano. PIMENTEL et al. (1983) depreenderam que os “inputs” relativos à mão-de-obra são substancialmente maiores para a tecnologia orgânica, quando comparada à "convencional”, afirmativa que é compartilhada por WAGSTAFF (1987). De acordo com GIAMPIETRO \& PIMENTEL (1990), pode-se assumir que a potência de um homem adulto é de 90 W e de uma mulher, também adulta, é de $60 \mathrm{~W}$. O nível de potência (expressa em Watts) per capita de trabalho humano é dada por (GIAMPIETRO \& PIMENTEL, 1990): Potência consumida per capita $=\left(x_{m} 90+x_{f} 60\right)$; em que: $x_{m}=$ percentual de 
trabalhadores adultos e $x_{f}=$ percentual de trabalhadoras adultas. BANSAL et al. (1988), trabalhando em regiões semi-áridas, consideraram para a atividade braçal de humanos valores de $0,22 \mathrm{MJ}$ $\mathrm{h}^{-1}$ para homens adultos e $0,18 \mathrm{MJ} \mathrm{h}^{-1}$ para mulheres.

Energia consumida relativa a fertilizantes e agrotóxicos

A produção e aplicação de agrofármacos pode representar pequena parcela da energia empregada na agricultura. De acordo com MATUO (1984), nos EUA a produção e aplicação desses produtos representam pouco mais de $5 \%$ do total de energia utilizada e isto representa $0,2 \%$ do total de consumo de energia. SEIXAS \& MARCHETTI (1982) estimaram que a agricultura brasileira utilizava $21 \%$ de sua energia na forma de combustíveis, 58\% na forma de fertilizantes, $14 \%$ na forma de agrotóxicos e 6,8\% para irrigação, transporte e outros. Para estes dados, os autores não consideraram a energia embutida nas máquinas.

Além dos aspectos energéticos da utilização de fertilizantes químicos, há que se considerar também as implicações ambientais. BOYELDIEU (1975) adverte que a valorização de resíduos, principalmente os orgânicos, deve ser considerada em razão do melhor aproveitamento de adubos e corretivos.

Energia empregada em edificações

Na determinação dos fluxos energéticos, principalmente nos grandes sistemas de produção, o pesquisador deve tipificar as instalações a serem utilizadas na composição dos balanços.

Trabalhando com dois tipos de residências, construídas com diferentes materiais, FERNANDES \& SOUZA (1982) encontraram consumo energético de $0,5^{\prime} 10^{6} \mathrm{kcalm}^{-2}$ e $0,24^{\prime} 10^{6} \mathrm{kcalm}^{-2}$ de área construída, respectivamente. Observaram que as paredes de tijolo cerâmico foram responsáveis por 66\% do conteúdo energético total, valor este superior ao conteúdo total da residência que empregou tijolos de concreto. DOERING III (1980) afirmou que, até à época, não havia análises dos vários tipos de estruturas empregadas no meio rural, sugerindo a utilização dos valores de 1.496.232 $\mathrm{kcal} \mathrm{m}^{-2}$ para residências e $409.041 \mathrm{kcal} \mathrm{m}^{-2}$ para construções de serviço. CAMPOS et al. (2003) determinaram o valor de $140.318 \mathrm{kcalm}^{-2}$ para instalações destinadas à conservação de feno, em sistema intensivo de produção de leite da Embrapa Gado de Leite, em Juiz de Fora/MG. Tomando-se como base somente a área útil (capacidade estática) para armazenagem dos fardos, este coeficiente energético seria de $148.717 \mathrm{kcal} \mathrm{m}^{-2}$. Em estudo de balanço de energia na produção de bovinos de leite e de suínos, QUESADA et al. (1987) se depararam com valores de $158.698 \mathrm{kcal}$ por vaca $\mathrm{ano}^{-1}$ e $829.530 \mathrm{kcal}$ por $100 \mathrm{~kg}$ de suíno, como coeficientes de energia empregada em instalações.

Uma análise da agricultura na ilha de Gotland, na Suécia, realizada por ZUCCHETTO \& JANSSON (1979), revelou que o item construções participava com apenas 2,3\% dentro da energia indireta. DELEAGE et al. (1979) contabilizaram o número e a área das construções e instalações rurais utilizadas na França. Os autores utilizaram valores equivalentes energéticos de 3,3GJ kg-1 para trabalhos de alvenaria e $56,1 \mathrm{GJ} \mathrm{kg}^{-1}$ para trabalhos com estruturas metálicas. Concluíram que, no ano de 1970, a agropecuária francesa utilizou um total de 41,2MGJ em construções e instalações. De acordo com PELLIZZI (1992), as construções rurais destinadas à produção de gado de leite contabilizam de 5 a 11\% do consumo específico de energia global, enquanto para as atividades de gado de corte e exploração de leite de ovinos, o consumo específico de energia para as instalações representa apenas 1 a $2 \%$ e 3 a $5 \%$, respectivamente.

\section{Delimitação do sistema}

Os limites de um sistema consumidor de energia podem ser determinados de várias maneiras, podendo incluir somente o poder calorífico de bens comerciais energéticos fornecidos diretamente para a atividade em estudo ou também podem incluir a energia comercial utilizada no suprimento de bens energéticos e outros "inputs”. O sistema energético pode também ser ampliado, incluindo fontes nãocomerciais, o trabalho muscular humano ou a energia do alimento. Finalmente, pode-se optar por incluir todo fluxo de energia solar que incide sobre a superfície da terra, ou alguma porção desta (DOVRING, 1985; COSTANZA, 1980).

A energia solar pode ser considerada gratuita, apresentando custo de oportunidade zero e sua não-contabilização, como ressalta COMITRE (1993), não implica maiores restrições ao método. A análise pode também ser enfocada no conceito de energia disponível. Da mesma forma, o combustível no subsolo (carvão mineral) pode ser tratado como não tendo valor, até que seja extraído (DOVRING, 1985).

\section{Conversão energética}

Define-se balanço de energia como atividade ou instrumento destinado a contabilizar as energias produzidas e as energias consumidas em 
determinado sistema de produção. Seu objetivo principal é traduzir em unidades ou equivalentes energéticos os fatores de produção e os consumos intermediários, possibilitando a construção de indicadores comparáveis entre si, que permitam a intervenção no sistema produtivo visando melhorar sua eficiência (BUENO et al., 2000). Observando a importância e utilidade deste instrumento, vários pesquisadores têm se utilizado dos balanços de energia para avaliação de sistemas e atividades agrícolas, nas mais diversas proporções, com distintas fronteiras (delimitações) do sistema. Esta preocupação com o emprego da energia na agricultura não é recente; SILVA \& GRAZIANO (1977) alertaram as autoridades responsáveis pela fixação de políticas para a pesquisa agropecuária, para a necessidade de direcionamento na busca de modelos poupadores de energia. Trabalhando com respostas aos diferentes níveis de nitrogênio, para diferentes culturas, Schuffelen, citado por BOYELDIEU (1975), encontrou grandes variações nos balanços de energia, destacando-se os valores de 8,4; 1,7 a 4,2; 1,3 a 3,4; 1,7 a 4,$2 ; 1,3$ a 6,3 e 0,8 a 1,7 ; para a relação (energia aplicada)/(energia obtida), para os produtos madeira, trigo, arroz, milho, batata e açúcar, respectivamente.

Avaliando os rendimentos energéticos dos vinte principais produtos agropecuários brasileiros entre as décadas de 1970 e 1990, COMITRE (1995) alega que, mesmo com o crescimento do uso de insumos, o rendimento energético aumentou. $\mathrm{O}$ autor atribui os resultados ao dinamismo, em termos de crescimento da produtividade, ocorrido na agricultura pelo processo de modernização.

Com o objetivo de fornecer subsídios para o estabelecimento de políticas de incentivos à produção ou de restrições ao consumo de energia, CASTANHO FILHO \& CHABARIBERY (1983) traçaram o perfil energético da agricultura paulista. Os índices encontrados indicaram que a agricultura se encontrava num estágio semelhante à de países desenvolvidos, como a França, mas mostraram a necessidade de se utilizar tecnologia menos dependente de fontes externas de energia. Um estudo no Estado de Santa Catarina revelou que os gastos energéticos são proporcionais ao grau de interferência mecânica e química nos ecossistemas, sendo que a tração motorizada e os insumos químicos (utilizados para fertilização e defesa da produção), segundo MELLO (1986), representaram os maiores custos energéticos.
O rendimento energético é dependente, outrossim, do nível tecnológico empregado. Analisando o cultivo de produtos diferenciados, CARMO et al. (1998) encontraram balanços muito diferentes entre as propriedades, sendo os grãos o produto de maior retorno por unidade calórica investida, e as hortaliças e produtos animais, exceto o mel, os menores. CARMO \& COMITRE (1991) determinaram os gastos energéticos para as culturas de soja e milho em algumas safras, entre 1965 e 1990. Segundo estes autores, os valores crescentes para o balanço indicaram aumento de produção de Mcal por Mcal investida, principalmente em função dos aumentos de produtividade. As fontes biológicas, de importância notória no início do período, foram sendo substituídas pelas de origem fóssil, sendo o combustível o mais expressivo, seguido de fertilizantes e corretivos.

Em estudo conduzido na região de Ribeirão Preto - SP, COMITRE (1993) avaliou o balanço energético nas fases agrícola, industrial e de distribuição da soja, obtendo valores de 5,77; 0,97; e 2,31; respectivamente.

Em três sistemas de produção de soja (semeadura com preparo convencional do solo, com preparo reduzido e direta), MESQUITA et al. (1982) observaram maior eficiência do sistema de semeadura direta no consumo de energia. A média de 717.000 $\mathrm{kcalha}^{-1}$ consumidas naquele sistema foi inferior em $39 \%$ e $20 \%$ àquelas dos sistemas convencional e reduzido, respectivamente.

Estudando o custo econômico e o custo energético, por meio de balanço de energia, na utilização de três sistemas de preparo do solo: preparo convencional, preparo com enxada rotativa e preparo conservacionista com escarificador, em combinação com quatro condições de cobertura do solo antes do preparo (aveia preta, centeio, nabo forrageiro e pousio mantido limpo durante o outono/inverno), BOLLER \& GAMERO (1997) verificaram que o preparo efetuado com enxada rotativa implicou investimento energético menor e que o preparo do solo demandou maior consumo energético no pousio em relação às parcelas onde houve cultivo anterior de aveia preta, centeio e nabo forrageiro. SANTOS \& REIS (1994), avaliando sistemas de rotação de culturas de cevada, propuseram um índice que relacionava o rendimento de grãos de cada espécie e a energia cultural despendida pelo uso de insumos e pelas operações realizadas: Produtividade cultural $\left(\mathrm{kgcal}^{-1}\right)=$ $\left\{\left[\right.\right.$ Rendimento de grãos $\left.\left(\mathrm{kgha}^{-1}\right)\right]$, [Energia cultural $\left(\right.$ calha $\left.\left.\left.^{-1}\right)\right]\right\}$. Concluíram que a eficiência energética foi influenciada pelo período agrícola, sendo que a aveia- 
branca e a cevada mostraram maiores índices de eficiência energética do que as demais culturas de inverno, e que o milho foi mais eficiente energeticamente. SANTOS et al. (2001) avaliaram a conversão e o balanço energético de sete sistemas de rotação de culturas, durante nove anos, de forma intercalada, na região de Passo Fundo/RS. Verificaram que todas as rotações de culturas foram mais eficientes do que a monocultura.

Em balanços de energia determinados por TSATSARELIS (1993) para o cultivo de trigo na Grécia, concluiu-se que a energia injetada, de acordo com o sistema de produção, oscilava entre 16.000 e 26.000MJ ha-1, sendo necessário adicionar de 1.500 a $3.000 \mathrm{MJ} \mathrm{ha}^{-1}$ quando se utilizava a irrigação. A maior parte da energia total inserida foi consumida pelos fertilizantes, incluindo aplicação. As intensidades energéticas calculadas situaram-se entre 2,35 a 2,90MJkg-1 e entre 2,58 a 3,13MJ kg-1 com o uso de irrigação. A eficiência energética variou entre 2,3 e 6,0 .

Em Botucatu, SP, SIQUEIRA et al. (1999) estimaram o balanço de energia na implantação de plantas de cobertura do solo (aveia preta, nabo forrageiro e tremoço azul), em preparo de solo convencional. Concluíram que, para a implantação e manejo da aveia e do nabo, o maior consumo de energia foi com combustível e fertilizantes; e, no caso do tremoço, foi com sementes e combustível.

Numa análise conduzida por ZUCCHETTO \& JANSSON (1979), verificou-se que a agricultura de Gotland (região ao norte da Suécia) tinha custo energético maior que a média dos Estados Unidos, porém representava pelo menos a metade do custo médio da agricultura de Israel. Nos custos de energia direta, incluíam-se 223TJ usados em combustíveis e 51,9TJ em eletricidade.

Em pesquisa delineando a distribuição de energia no sistema agrícola de toda a França, para o ano de 1970, DELEAGE et al. (1979) estimaram um consumo de energia de 569,5MGJ naquele ano, correspondendo a 9,4\% do consumo energético nacional, sendo 4,36\% para participação no consumo indireto e 4,64\% no consumo direto. Eles depreenderam também que somente $11,2 \%$ do total advinha de fontes de energia renováveis.

Apesar da grande tendência demonstrada na literatura, no intuito de chamar a atenção da má utilização e baixa eficiência energética na agricultura, alguns trabalhos têm demonstrado críticas no sentido contrário. Ainda na França, BONNY (1993) estudou a eficiência de utilização de energia na agricultura, entre 1959 e 1989 e notou que foi necessário incremento na quantidade de energia direta para um dado volume de produção; porém, desde 1977 esta quantidade vem diminuindo, o que levou o autor a crer que a agricultura se tornou mais eficiente no uso de energia naqueles últimos anos. Entretanto, ele admite ter utilizado somente dados de energia direta (combustíveis sólidos, eletricidade e gás, diretamente consumidos na agricultura), não levando em conta a energia indireta (empregada na manufatura de diferentes "inputs” utilizados, como fertilizantes, agrotóxicos, maquinário, etc.), restringindo os resultados deste trabalho.

Fluxos de energia e determinação do valor da eficiência energética visando à sustentabilidade da agricultura dinamarquesa foram o foco do estudo de SCHROLL (1994). O autor observou que a eficiência energética foi decrescendo à medida que problemas ambientais relativos à produção agrícola foram aparecendo no período estudado (1936 a 1990). O autor afirmou que, quando a saída de energia na alimentação humana se iguala à quantidade de energia fóssil despendida para produzi-la, não parece ser ecologicamente sustentável, e o autor argumentou que as duas principais maneiras para se aumentar a eficiência energética média do país seriam: 1) Encorajar maior produção de alimentos para os seres humanos em detrimento dos animais; 2) Reduzir a entrada de energia fóssil, especialmente aquela relacionada à aplicação de fertilizantes. É importante destacar que as soluções são sempre locais, dependendo das características, onde se inclui até a extensão do país. Para o caso brasileiro, pode-se estudar medidas menos radicais, como tentativa de racionalizar a alimentação animal, utilizando-se maior quantidade de volumosos de alto valor nutritivo para buscar maior eficiência na utilização de fontes não renováveis de energia, contribuindo para a sustentabilidade dos agroecossistemas.

Um dos campos em que o método de cálculo de balanço de energia se mostra imperativo foi na produção de combustíveis. Nesses casos, devese investigar se um dado sistema produz mais energia (na forma de combustível) do que consome. HELENE et al. (1981) determinaram o balanço de energia para a produção de etanol a partir da hidrólise ácida da madeira. Perceberam que os gastos de energia na fase agrícola do processo correspondeu a aproximadamente $1 \%$ do total, enquanto para a cana de açúcar foi de $15 \%$ do total gasto. A relação entre a energia contida no combustível e a energia total gasta para produzi-lo, por meio de madeira de pinus, de eucalipto e de cana-de-açúcar, foram de 0,62; 0,45 e 0,80 ; respectivamente.

Ciência Rural, v.34, n.6, nov-dez, 2004. 
Destaca-se o fato de que os balanços energéticos foram úteis, mas deve-se procurar sempre aprimoramento nos métodos (DOVRING, 1985). Existe, ainda, uma infinidade de fatores que provocam variação nos resultados para um mesmo produto agrícola. No Brasil, existem distintas formas de conduzir uma dada cultura ou criar uma determinada espécie animal. Fatores tais como tipo de solo, topografia (inclinação, altitude, exposição solar) do terreno podem provocar diferenças consideráveis no consumo de energia. Somando-se todas estas fontes de variação, pode-se dizer que até mesmo a tradição local pode introduzir diferenças nos processos produtivos.

\section{CONCLUSÕES}

Mesmo quando não são completamente precisos, os dados relacionados a consumo e eficiência energética constituem poderosas ferramentas de diagnóstico de sistemas produtivos agrícolas. Pela existência de numerosos trabalhos neste sentido em todas as partes do mundo, justificam-se mais estudos. GIAMPIETRO et al. (1992) consideram as análises energéticas e indicadores relacionadores de energia como um método promissor para avaliar e investigar os problemas relacionados à sustentabilidade e à eficiência de sistemas agrícolas. Porém, no Brasil os pesquisadores têm demonstrado pouco interesse no desenvolvimento de trabalhos de balanço de energia como meio de avaliar processos produtivos. O estudo seriado e persistente pode fornecer subsídios para que pesquisadores desenvolvam estudos sobre balanço energético específico para as várias áreas da agropecuária. A determinação de informações específicas para as condições brasileiras serão primordiais para a continuidade da pesquisa no setor.

A utilização de balanços de energia pode constituir-se importante instrumento para definição de novas técnicas e manejos agropecuários, que podem vir a proporcionar importante economia de energia e, conseqüentemente, aumento de eficiência e redução de custo de produção, em sistemas de produção mais tecnificados, que possuem utilização intensiva de energia em suas várias formas. BOYELDIEU (1975) ressalvou que os responsáveis pela orientação agrícola, tais como extensionistas, podem contribuir muito, auxiliando na transmissão de resultados e orientações a partir dos estudos desenvolvidos.

Pôde-se concluir, outrossim, que ainda não existe uma metodologia padronizada para a estimativa de balanços de energia, para as diversas regiões do globo. Considerando as condições brasileiras de um país com dimensões continentais, caracterizado por grandes diferenças edafo-climáticas e sociais, estabelecer um paradigma considerado definitivo para o desenvolvimento de balanços de energia seria um grande desafio, senão uma utopia, à medida que notase uma carência acentuada de trabalhos na área, que venham a contribuir com o levantamento de dados e coeficientes energéticos mais específicos, visando à composição de matrizes energéticas para estas condições. Sendo uma ciência em desenvolvimento, caracterizada inclusive por possibilitar escolha de classificações e métodos de forma subjetiva, é necessário que haja maior exploração por parte dos pesquisadores brasileiros preocupados com a questão da sustentabilidade dos agroecossistemas. É necessário visar, em uma primeira instância, o levantamento e a publicação de coeficientes energéticos relacionados aos produtos, equipamentos, insumos e instalações característicos brasileiros, de forma semelhante aos trabalhos coordenados por PIMENTEL (1980), que venham a fornecer subsídios para o desenvolvimento de balanços energéticos com melhor nível de precisão.

\section{REFERÊNCIAS BIBLIOGRÁFICAS}

BANSAL, R.K.; KSHIRSAGAR, K.G.; SANGLE, R.D. Efficient utilization of energy with an improved farming system for selected semi-arid tropics. Agriculture, Ecosystems and Environment, Amsterdam, v.24, n.4, p.381-394, 1988.

BOLLER, W.; GAMERO, C.A. Estimativas dos custos econômicos e energéticos de sistemas de preparo e de manejo do solo para a cultura do feijão. Energia na Agricultura, Botucatu, v.12, n.2, p.26-38, 1997.

BONNY, S. Is agriculture using more and more energy? A French case study. Agricultural Systems, Essex, UK, v.43, n.1, p.5166, 1993.

BOYELDIEU, J. Rendement énergétique de la production agricole: les bilans d'énergie. Agriculture, Paris, v.386, p.124$128,1975$.

BUENO, O.C. Análise energética e eficiência cultural do milho em assentamento rural, Itaperá/SP. 2002. 146f. Tese (Doutorado em Energia na Agricultura) - Curso de Pós-graduação em Agronomia, Faculdade de Ciências Agronômicas, Universidade Estadual Paulista, São Paulo.

BUENO, O.C.; CAMPOS, A.T.; CAMPOS, A.T. Balanço de energia e contabilização da radiação global: simulação e comparativo. In: AVANCES en Ingeniería Agrícola. Buenos Aires : Editorial Facultad de Agronomía, 2000. p.477-482.

CAMPOS, A.T. Balanço energético relativo à produção de feno de “coast-cross” e alfafa em sistema intensivo de produção de leite. 2001. 236f. Tese (Doutorado em Energia na Agricultura) - Curso de Pós-graduação em Agronomia, Faculdade de Ciências Agronômicas, Universidade Estadual Paulista, São Paulo. 
CAMPOS, A.T. et al. Balanço energético na produção de silagem de milho em cultivos de verão e inverno com irrigação. In: AVANCES en Ingeniería Agrícola. Buenos Aires : Editorial Facultad de Agronomía, 2000. p.483-488.

CAMPOS, A.T. et al. Custo energético de construção de uma instalação para armazenagem de feno. Ciência Rural, Santa Maria, v.33, n.4, p.667-672, 2003.

CARMO, M.S.; COMITRE, V. Evolução do balanço energético nas culturas de soja e milho no Estado de São Paulo. In:CONGRESSO BRASILEIRO DE ECONOMIA E SOCIOLOGIA RURAL, 29., 1991, Campinas. Anais... Brasília : Sociedade Brasileira de Economia e Sociologia Rural, 1991. p.131-149.

CARMO, M.S.; COMITRE, V.; DULLEY, R.D. Balanço energético de sistemas de produção na agricultura alternativa. Agricultura em São Paulo, São Paulo, v.35, n.1, p.87-97, 1988.

CARVALHO, A.; GONÇALVES, G.G.; RIBEIRO, J.J.C. Necessidades energéticas de trabalhadores rurais e agricultores na sub-região vitícola de Torres. Lisboa : Fundação Calouste Gulbenkian, 1974.

CASTANHO FILHO, E.P.; CHABARIBERY, D. Perfil energético da agricultura paulista. Agricultura em São Paulo, São Paulo, v.30, tomos 1 e 2, p. 63-115, 1983.

CLEVELAND, C.J. The direct and indirect use of fossil fuels and electricity in USA agriculture, 1910-1990. Agriculture, Ecosystems and Environment, Amsterdam, v.55, n.2, p.111121, 1995.

COMITRE, V. A questão energética e o padrão tecnológico da agricultura brasileira. Informações Econômicas, São Paulo, v.25, n.12, p.29-35, 1995.

COMITRE, V. Avaliação energética e aspectos econômicos da filière soja na região de Ribeirão Preto-SP. 1993. $152 \mathrm{f}$. Tese (Mestrado em Engenharia Agrícola/Planejamento Agropecuário) - Faculdade de Engenharia Agrícola, Universidade Estadual de Campinas.

COSTA BEBER, J.A. Eficiência energética e processos de produção em pequenas propriedades rurais, Agudo, RS. 1989. 295f. Disseertação (Mestrado em Extensão Rural) - Universidade Federal de Santa Maria.

COSTANZA, R. Embodied energy and economic valuation. Science, N.Y. (USA), v.210, p.1219-1224, 1980.

DELEAGE, J.P.et al. Eco-energetics analysis of an agricultural system: the French case in 1970. Agro-ecosystems, Amsterdam, v.5, p.345-365, 1979.

DOERING III, O.C. Accouting for energy in farm machinery and buildings. In: PIMENTEL, D. (Ed.). Handbook of energy utilization in agriculture. Boca Raton : CRC, 1980. p.9-14.

DOVRING, F. Energy use in Unites States agriculture: a critique of recent research. Energy in Agriculture, v.4, p.79-86, 1985.

FERNANDES, M.P.; SOUZA, A.M.T. Balanço energético - o consumo de energia na construção civil. Revista Brasileira de Tecnologia, Brasília, v.13, n.3, p.22-36, 1982.

FERREIRA, W.A.; ULBANERE, R.C. Análise do balanço econômico para a produção de milho no estado de São Paulo. Ener- gia na Agricultura, Botucatu, v.4, n.2, p.8-18, 1989.

FLUCK, R.C. Energy productivity: a measure of energy utilization in agricultural systems. Agricultural Systems, Essex, UK, v.4, n.1, p.29-37, 1979.

FLUCK, R.C. Net energy sequestered in agricultural labor. Transactions of the ASAE, St. Joseph, Michigan, v.24, n.6, p.14491455, 1981.

FLUCK, R.C. To evaluate labor energy in food production. Agricultural Engineering, v.57, n.1, p.31-32, 1976.

GiAmpietro, M.G.; CERRETELli, G.; PIMENTEL, D. Energy analysis of agricultural ecosystem management: human return and sustainability. Agriculture, Ecosystems and Environent, v.38, n.3, p.219-244, 1992.

GIAMPIETRO, M.G.; PIMENTEL, D. Assessment of the energetics of human labour. Agriculture, Ecosystems and Environment, Amsterdam, v.32, n.3-4, p.257-272, 1990.

GUERRERO, J.S.J. Dimensão teórica da energia, economia e sociedade: integração no desenvolvimento da humanidade. Revista de Economia Rural, v.25, n.3, p.293-301, 1987.

HELENE, M.E.M.; GRAÇA, G.M.; GOLDEMBERG, J. Etanol de madeira - balanço energético. Ciência e Cultura, São Paulo, v.33, n.9, p.1183-1191, 1981.

JUNQUEIRA, A.A.B.; CRISCUOLO, P.D.; PINO, F.A. O uso da energia na agricultura paulista. Agricultura em São Paulo, São Paulo, v.29, tomos I e II, p.55-100, 1982.

MATUO, T. Técnicas de aplicação de defensivos. In: SIMPÓSIO SOBRE ENERGIA NA AGRICULTURA, TECNOLOGIAS POUPADORAS DE INSUMOS, INTEGRAÇÃO DE SISTEMAS ENERGÉTICOS E PRODUÇÃO DE ALIMENTOS, 1., 1984, Jaboticabal. Anais... Jaboticabal : FCAV/UNESP, 1984. p.113130.

MELLO, R. Análise energética de agroecossistemas: o caso de Santa Catarina. 1986. 139f. Dissertação (Mestrado em Engenharia/Engenharia de Produção) - Departamento de Engenharia de Produção e Sistemas, Universidade Federal de Santa Catarina, Florianópolis.

MESQUiTA, C.M.; ROESSING, A.C.; GAZZIERO, D.L.P. Consumo de energia e avaliação técnica-econômica de sistemas de produção de soja. I n: SEMINÁRIO NACIONAL DE PESQUISA DE SOJA, 2., 1981, Brasília. Anais... Londrina : Centro Nacional de Pesquisa de Soja/EMBRAPA, 1982. V.1, p.525-538.

PELLIZZI, G. Use of energy and labour in Italian agriculture. Journal of Agricultural Engineering Research, Silsoe, v.52, n.2, p.111-119, 1992.

PIMENTEL, D. (Ed) Handbook of energy utilization in agriculture. Boca Raton: CRC, 1980. 475p.

PIMENTEL, D. et al. Food production and the energy crises. Science, N.Y. (USA), v.182, p.443-449, 1973.

PIMENTEL, D.; BERARDI, G.; FAST, S. Energy efficiency of farming systems: organic and conventional agriculture. Agriculture, Ecosystems and Environment, Amsterdam, v.9, n.4, p.359-372, 1983.

Ciência Rural, v.34, n.6, nov-dez, 2004. 
QUESADA, G.M.; COSTA BEBER, J.A.; SOUZA, S.P. Balanços energéticos: uma proposta metodológica para o Rio Grande do Sul. Ciência e Cultura, São Paulo, v.39, n.1, p.20-28, 1987.

RIVALDO, O.F. Energia na agricultura. In: LEVON, Y.(Org.). Pesquisa agropecuária, questionamentos, consolidação e perspectivas. Brasília : EMBRAPA, 1988. p.267-268.

SANTOS, H.P. et al. Conversão e balanço energético de sistemas de sucessão e de rotação de culturas. Ciência Rural, Santa Maria, v.31, n.2, p.191-198, 2001.

SANTOS, H.P.; REIS, E.M. Rotação de culturas em Guarapuava XVII - eficiência energética dos sistemas de rotação de culturas para cevada, em plantio direto. Pesquisa Agropecuária Brasileira, Brasília, v.29, n.7, p.1075-1081, 1994.

SCHROLL, H. Energy-flow and ecological sustainability in Danish agriculture. Agriculture, Ecosystems and Environment, Amsterdam, v.51, n.3, p.301-310, 1994.

SEIXAS, J.; MARCHETTI, D. Produção e consumo de energia na agricultura. Planaltina: EMBRAPA - Centro de Pesquisa Agropecuária dos Cerrados, 1982. 15p. (EMBRAPA-CPAC. Documentos, 3).
SILVA, J.G.; GRAZIANO, J.R. A crise de energia: repensar também a pesquisa agronômica. Ciência e Cultura, São Paulo, v.29, n.10, p.1110-1116, 1977.

SIQUEIRA, R.; GAMERO, C.A.; BOLLER, W. Balanço de energia na implantação e manejo de plantas de cobertura do solo. Engenharia Agrícola, Jaboticabal, v.19, n.1, p.80-89, 1999.

TSATSARELIS, C.A. Energy inputs and outputs for soft winter wheat production in Greece. Agriculture, Ecosystems and Environment, Amsterdam, v.43, n.2, p.109-118, 1993.

ULBANERE, R.C.; FERREIRA, W.A. Análise do balanço energético para a produção de milho no estado de São Paulo. Energia na Agricultura, Botucatu, v.4, n.1, p.35-42, 1989.

WAGSTAFF, H. Husbandry methods and farm systems in industrialized countries which use lower levels of external inputs: a review. Agric. Ecosystems Environment, Amsterdam, v.19, n.1, p.1-27, 1987.

ZUCCHETTO, J.; JANSSON, A-M. Total energy analysis of Gotland's agriculture: a northern temperature zone case study. Agro-ecosystems, Amsterdam, v.5, p.329-344, 1979. 